\title{
VEGETATION EFFECTS IN BRAIDED RIVERS WITH ERODIBLE BANKS
}

\author{
Chang-Lae JANG ${ }^{1}$, Yasuyuki SHIMIZU ${ }^{2}$ and Takao MIYAZAKI ${ }^{3}$ \\ ${ }^{1}$ Student Member of JSCE, Ph.D.student, Division of Environmental and Resource Engineering, \\ Hokkaido University (North 13, West 8, Kita-ku, Sapporo, Hokkaido, 060-8628, Japan) \\ ${ }^{2}$ Member of JSCE, Associate Prof., Division of Environmental and Resource Engineering, Hokkaido \\ University (North 13, West 8, Kita-ku, Sapporo, Hokkaido, 060-8628, Japan) \\ ${ }^{3}$ Dept. of Civil Engineering, Hokkaido Univeristy (North 13, West 8, Kita-ku, Sappro, Hoakkido, \\ 060-8628, Japan)
}

\begin{abstract}
Laboratory experiments were carried out to elucidate the influence of riparian vegetation on braided rivers with unconstrained banks. One run for barided river without vegetation from initial straight channel and two kinds of runs for the river with vegetation were conducted. For the vegetated braided river alfalfa seed was introduced to the channel by controlling the density. In this study, flow characteristics and channel evolution to explain vegetation effects in braided river were investigated . Especially in morphological behavior, a primary channel was developed to a high meandering channel and bifurcated to two channels due to vegetation on the bed and banks. And numerical model is applied to investigate the effect of vegetation in braided river with and without vegetation and the results are discussed.
\end{abstract}

Key Words: braided river, channel evolution, vegetation, alfalfa

\section{INTRODUCTION}

The morphological behavior in braided rivers with erodible banks is governed by a lot of factors. Especially vegetation makes an important role in the channel evolution(Fig. 1), and better understanding of its influence is of great importance in the aspect of hydraulic and environmental engineering. However, it has been much restricted since the behavior of vegetated rivers is complex.

Numerous theoretical and experimental investigations have been done to explain the mechanical processes of braided rivers. And the formation processes of braided river from initially straight channels with erodible bed and banks have been investigated by Ashmore $(1982,1991)$ experimentally. He pointed out that the development of bars brought about channel migration and divison.

Andrews (1984), Hey and Thorne(1986), and Huang and Nanson(1997) have explained from the field obser- vations that highly concentrated vegetation increases the channel depth and flow resistance and decreases channel width.

A theoretical model was suggested by Ikeda and Izumi (1990) to elucidate the relation between the vegetation density and the hydraulic factors, for exanple, the channel depth, the widhh, and discharge in the self-formed straight gravel rivers, in which the vegetation was assumed to be stiff without considering the bending effect. Gran and Paola(2001) reproduced a wandering channel from a braided river by controlling vegetation density to explain that riparian vegetation affect braided channel form and flow characteristics by itself. Shimizu(2002) proposed a numerical model to simulate braided rivers with erodible banks, and showed the possibility of simulating braided rivers without vegetation considering bank erosion.

In this study, channel evolution of braided river with erodible bed and banks covered with and without vegetation experimenally and numerically is investigated 


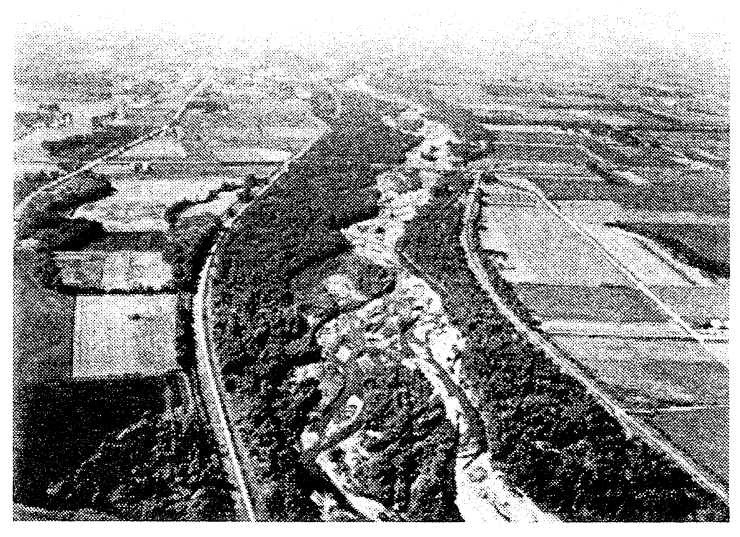

Fig.1 Braided river with erodible banks covered with vegetation (Satsunai river, Hokkaido).

cosisdering its hydraulic characteristcis, that is, flow resistance, and water depth.

\section{EXPERIMENTAL PROCEDURES}

Laboratory experiments were carried out in a flume with $12 \mathrm{~m}$ in length and $2 \mathrm{~m}$ in width, and sidewalls of the flume were wooden plates. The flume was filled with well sorted-sand with $1.25 \mathrm{~mm}$ of mean diameter. An initial channel was set to trapezoidal shape with 80 $\mathrm{cm}$ at the bottom, $3 \mathrm{~cm}$ at the height, and 40 degree at the bank slope. Water discharge was controlled to 3.5 $l / s$ under the initial conditions. The non-dimensional channel (width/depth ratio) was 85.3. Experimental conditions are summarized at Table 1.

Sediments were given by hand regularly at the upstream end of the channel to maintain the channel shape without local disturbance during the experiments. The bed was graded to the intended slope by using a wide scraper and the initial channel was cut by a wooden prototype attached to the lower end of the scraper at the same time. Before starting the experiment, a little water flowed over the bed to saturate the bed surface. Water depth was checked at some places using a point gage after 15 minutes of water flow.

Table 1 Experimental Conditions

\begin{tabular}{|c|c|c|}
\hline Run & $\begin{array}{c}\text { Bed slope } \\
(\%)\end{array}$ & $\begin{array}{c}\text { Veg. Density } \\
\left(\text { stems } / \mathrm{cm}^{2}\right)\end{array}$ \\
\hline 1 & 1.5 & 0.0 \\
\hline 2 & 1.5 & 0.7 \\
\hline 3 & 1.5 & 1.1 \\
\hline
\end{tabular}

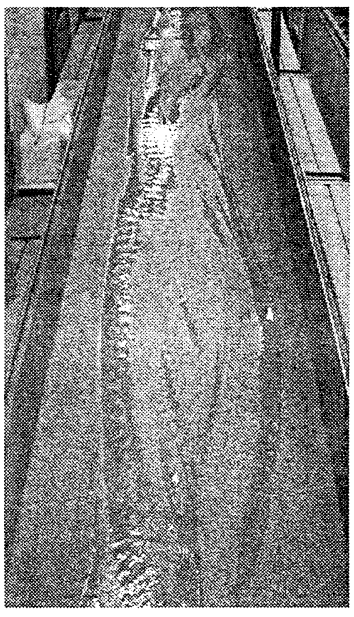

(a)

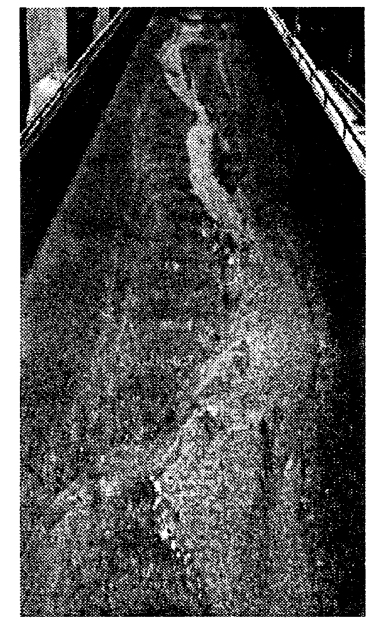

(b)
Fig. 2 Reproduced braided river in laboratory from initially straight channel (a) without vegetation for Run-1 and (b) with vegetation for Run-3. Flow is from up to down.

Plastic mesh screen was set to maintain nearly steady state inflow into the channel at the front of the channel inlet, and water depth was regulated by sluice gate to minimize the outlet effect at the downstream end of the channel. Bed configuration was measured using a laser bed profiler without water flow.

The longitudinal bed profile was measured from 1 $\mathrm{m}$ at the upstream to $8 \mathrm{~m}$ at every $20 \mathrm{~cm}$ in the experimental reach since the upstream $1 \mathrm{~m}$ was not considered to avoid the effects of inlet and disturbance of water profile due to the sediment supply. The transverse bed profile was surveyed between $0.05 \mathrm{~m}$ and $1.95 \mathrm{~m}$ at every $1 \mathrm{~cm}$ due to the moving limitation of the profiler.

After the braided channel was fully reproduced, which was 64 minutes, we sprayed alfalfa seed on the channel bed and banks by hand uniformly without the flow. After that, discharge of $0.4 \mathrm{l} / \mathrm{s}$ was allowed in the channel for 2 minutes to prevent alfalfa from growing up at the lower channel, and it similar to natural rivers, as shown in Fig. 1, during lower flow period. The seed was scattered on bars and banks, some were transported on the lower channel bed by the flow and later placed along the banks, border line between bar and water elevation, or washed out the flume. It is similar to the observations of Gran and Paola(2001) in the laboratory flume. The discharge of $0.15 \mathrm{l} / \mathrm{s}$ had been allowed to the channel to maintain the saturated 


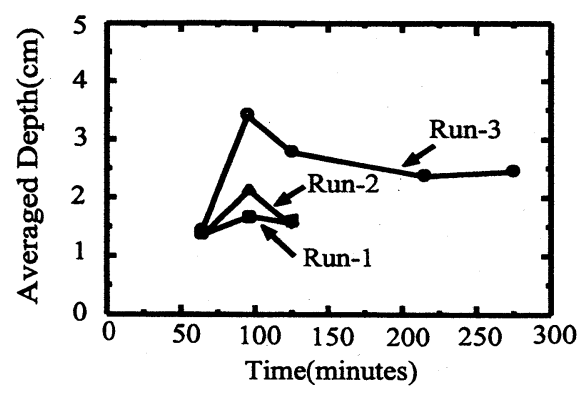

(a) Averaged water depth at $6 \mathrm{~m}$ from the upstream for each run

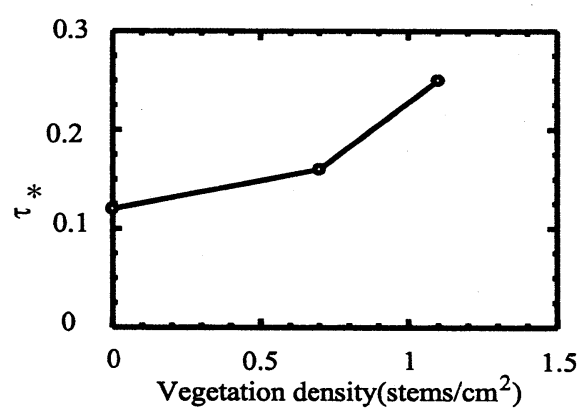

(b) Tractive force with vegetation density

Fig. 3 Averaged water depth and tractive force

bed, leading to keep the channcl shapes, and to supply water to alfalfa by two times per day about 1.5 hours. We continued the runs for additional run time after alfalfa sprout had grown for two weeks to sustain the flow, and the alfalfa was composed of a stem of about $3.5 \mathrm{~cm}$ high and $1 \mathrm{~mm}$ in diameter with 3 leaves. Roots length was about $3 \mathrm{~cm}$. Alfalfa density was estimated using the weight of the seed before spreading it considering the sprout rate $(80 \%)$, which was the specified minimum rate of a seed company, and loss rate (1\%), which was the assumed rate. One example is presented in Fig. 2.

\section{EXPERIMENTAL RESULTS}

Vegetation affects the characterists of the flow, that is, flow depth, velocity, and directions , in fluvial steams, resulting in the channel evolution. Fig. 3(a) displays the water depth with vegetation density. As vegetation density increased in the bed and banks, the depth was increased. Numerous studies have elucidated the relation between vegetation density and water depth by field survey, experiment, and theory (Andrws 1984; Gran and Paola 2001; Tsujimoto 1999).

Fig. 3(b) shows the calculated dimensionless shear stress with riparian vegetation density. As the vegetation density increased, the shear stress increased

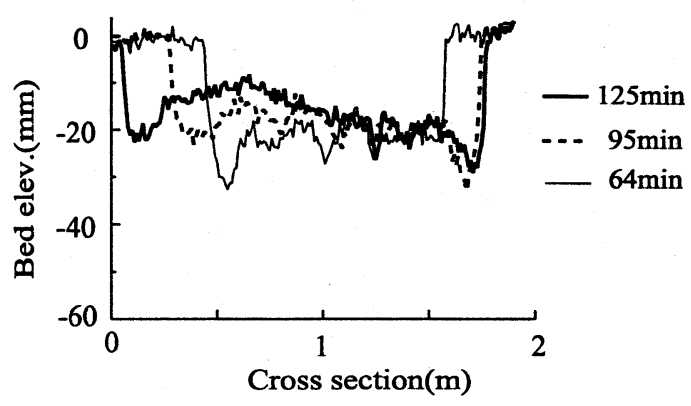

(a)

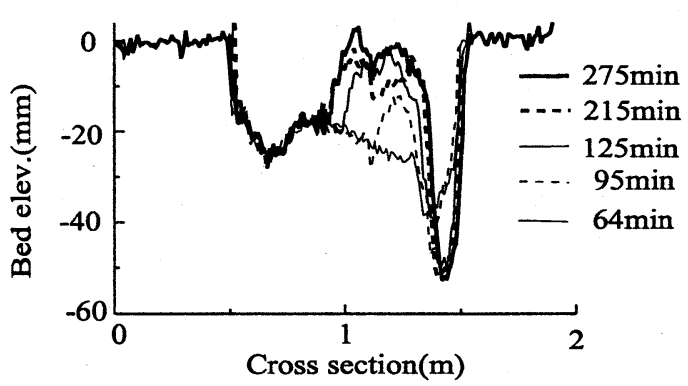

(b)

Fig. 4 Cross sectional changes at $6 \mathrm{~m}$ from the upstream ; (a) without vegetation for Run-1 and (b) with vegetation for Run-3.

linearly, which was the same as observations of Bennett et al. (2002). Fig. 4 illustrates the more quantative comparison of cross sectional changes at $6 \mathrm{~m}$ from upstream for Runs-1 and 3. As time progressed, lateral erosion of bank in the channel without riparian vegetation increased larger than with the vegetation from Figs. 4 and 5. And the bed eroded deeply and the width narrowed owing to the reinforeced bank by vegetation root.

The bed of main channel, which was a lower channel without vegetation in the reproduced braided river, was scoured as time progressed although secondary channels, which were higher channels covered with vegetations in the braided river, were not changed. As vegetation density increased, bank erosion rate was lower because vegetation root reinforced bank materials and the vegetation density increased flow resistance.

Because of the roughness of vegetation near the bank side as a bank protector, the flow did not impinge directly on banks, which were reinforced by vegetation root. Flow direction was controlled by vegetation, and the bed was deepened due to the secondary flow.

As time progressed, the weakly meandered bank eroded because of the concentrated secondary flow, 


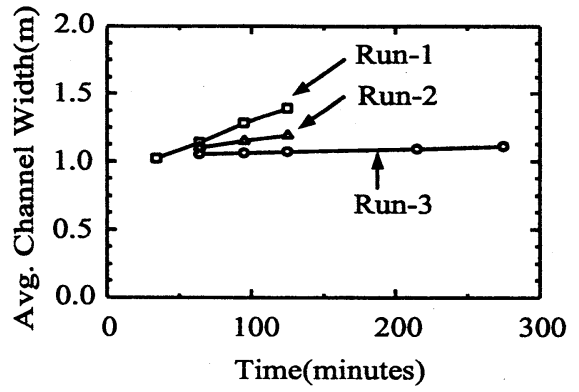

Fig. 5 Comparison of averaged channel width for each run.

and the main channel in the braided river became high meandering channel. At the place the bed was deeper and the flow direction was changed due to the higher bed and log-jam effect. As time increased the down stream of the bed eroded in turn due to the flow through the vegetation and log-jam, and a new channel occurred. At the opposite side scour hole at the confluence channel was developed and the curvature of the channel became larger. This mechanism is different from it without vegetation, illustrated by Fujita and Muramoto(1982) and Ashmore (1982, 1991).

\section{NUMERICAL SIMULATION}

A numerical model was applied to investigate the effect of vegetation in braided river with and without vegetation.

The governing equations, continuity and momentum equaitons, for water flow are transformed the Cartesian coordinate system to a moving boundary fitted coordinate system due to the deformation of side banks. The equations in the moving boundary fitted coordinate system are explained in Shimizu(2002).

The continuity equation of two-dimensional bedload transport in the moving boundary fitted coordiante systm is represented as follows:

$$
\frac{\partial}{\partial t}\left(\frac{z_{b}}{J}\right)+\frac{1}{1-\lambda}\left[\frac{\partial}{\partial \xi}\left(\frac{q^{\xi}}{J}\right)+\frac{\partial}{\partial \eta}\left(\frac{q^{\eta}}{J}\right)\right]=0
$$

where $z_{b}$ is bed elevation, $\lambda$ is porosity of bed material, and $q^{\xi}$ and $q^{\eta}$ are the contravariant components of the bedload transport rate per unit width in the $\xi$ - and $\eta$ - directions. The sediment transport rate in the stream line, $q^{s}$, is calculated by using Ashida and Michiue's formula(1972) modified by Hasegawa(2000) to explain the effect of bank slope considering the gravitaional effect on the side bank proposed by Kovac and Parker(1994).

$$
\begin{array}{r}
q^{s}=\frac{17}{\cos \theta_{b}} \tau_{*}^{3 / 2}\left(1-\frac{\tau_{* c}}{\tau_{*}}\right)\left[1-\sqrt{\frac{2 \tau_{* c} \cos \theta_{b}}{\tau_{*}}}+\right. \\
\left.2\left(\tan \theta_{b}-\frac{\partial z_{b}}{\partial s}\right)\right] \sqrt{\left(\frac{\rho_{s}}{\rho}-1\right) g d^{3}}
\end{array}
$$

where $\theta_{b}$ is channel reference slope in downstream direction, $\rho_{s}$ is density of bed material, $d$ is grain size of bed material, $\tau_{*}$ is non-dimensional bed shear stress, and $\tau_{* c}$ is critical non-dimensional bed shear stress obtained by using Iwagaki's equation. $q^{n}$ is given by the following formula proposed by Hasegawa (2000).

$$
q^{n}=q^{s}\left(\frac{h}{r_{s}} N_{*}-\sqrt{\frac{2 \tau_{* c} \cos \theta_{b}}{\tau_{*}}} \frac{\partial z_{b}}{\partial n}\right)
$$

where $r_{s}$ is the radius of curvature of a streamline, $N_{*}$ is the coefficient of strength of secondary flow. In the analysis, a constant of $N_{*}=7.0$ given by Engelund (1974) is used.

The CIP method was used as a numerical scheme. On calculation of bank erosion, numerical algorithm following Shimizu's(1996) was employed.

Although the bed roughtness and drag froce of vegetation must be cosidered to simulate vegetation effects seperately(Tsujimoto 1999, and among others), as a preliminary study, we assumed that the Manning's roughness coefficient was 0.012 without vegetation for Run-1 and 0.017 with vegetation for Run-3 simply considering water depth, instead of ingnoring the drag force of vegetation, and also we are trying to improve this weak point in this model. The angle of repose was set to 24.4 degree for Run-1 and 47.7 degree for Run-3.

\section{NUMERICAL RESULTS}

We display in Fig. 6 numerically and experimentally that a braided river is shown up from initially straight channel and is remarkly developed while the channel width is enlarged since the side banks eroded. And also the mechanism of braided river under large aspect ratio explained by Ashmore(1991) were illustrated for Run-1. Flow was concentrated into lower channels, and some of them eroded deeply. Bars appeared to the downstream of the lower channels and complicated braided bars were developed due to flow 


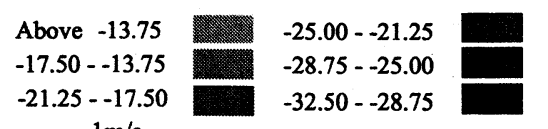

$-21.25--17.50$

$-1 \mathrm{~m} / \mathrm{s}$

$-32.50--28.75$

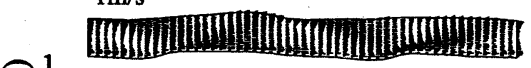

$\overbrace{}^{1} 0$

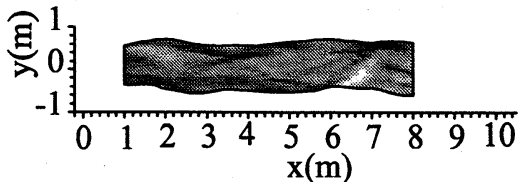

(a) $\mathrm{T}=64 \mathrm{~min}$

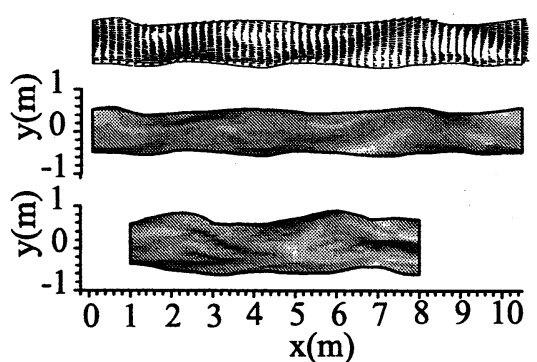

(b) $\mathrm{T}=95 \mathrm{~min}$

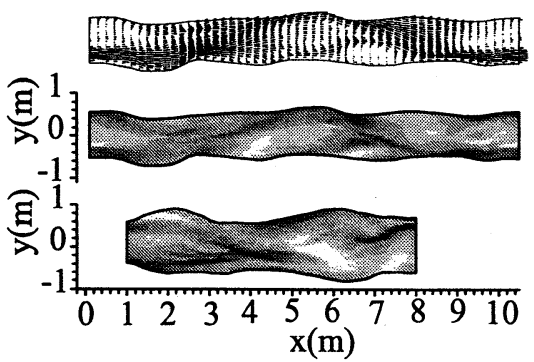

(c) $\mathrm{T}=125 \mathrm{~min}$
$-36.25--32.50$

$-40.00--36.25$

Below -40.00

Unit:mm

Calculation

Experiment

Calculation

Experiment

Calculation

Experiment

Fig. 6 Comparison of channel evolution between calculation and experiment, and calculated velocity patterns for Run-1.

division around bars, leading to bank erosion. Fig. 7 shows that the width narrowed and the bed eroded deeper because of the steeper angle of repose due to the stabilized banks by vegetation.

Figs. 8 and 9 display the more quantitative comparison of cross sectional changes at $6 \mathrm{~m}$ from the upstream for Runs-1 and 3. The comparison of cross sectional changes between calculation and experiment for Run1 and Run-3, respectively, showed a little difference, because of the poorly treated results of boundary between the dried and wetted parts of the bar in the channel. The calculation results are overall in good agreement with the experimental results, although the longitudial wavelength and thalweg of the channel in the calculation are a little difference from those in the experiment.

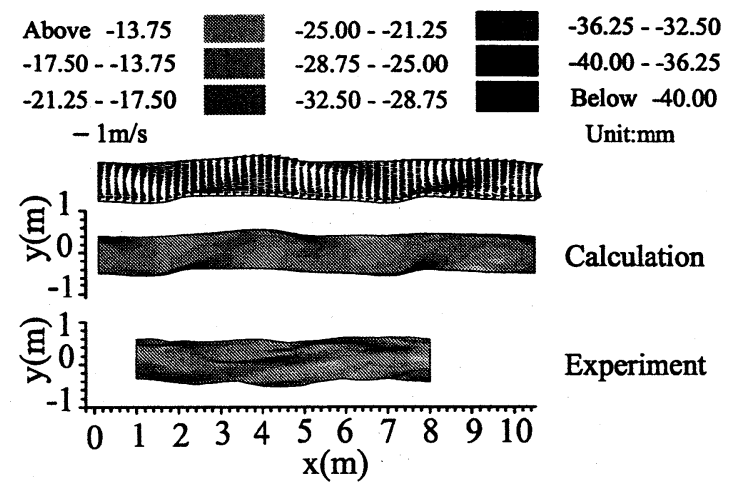

(a) $\mathrm{T}=64 \mathrm{~min}$
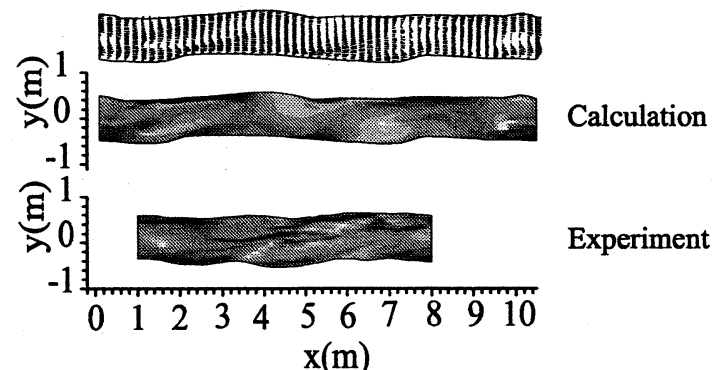

Experiment

(b) $\mathrm{T}=95 \mathrm{~min}$
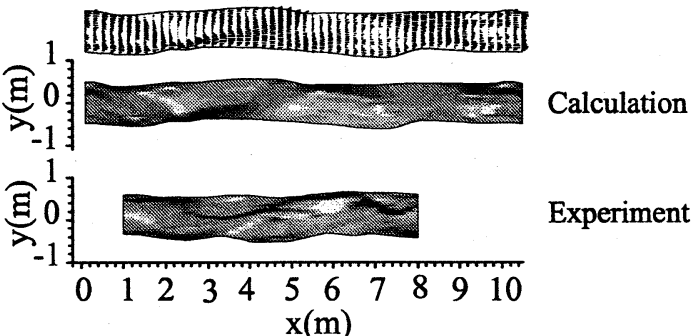

(c) $\mathrm{T}=125 \mathrm{~min}$

Experiment

Fig. 7 Comparison of channel evolution between calculation and expeeriment, and calculated velocity patterns for Run-3.

\section{CONCLUSIONS}

In this study, flow characteristics and channel evolution to explain vegetation effects in braided river were investigated experimentally and numerically. The flow depth, velocity, and directions were influenced by vegetation. As the vegetation density increased in the bed and banks, the depth was increased because of the flow resistance.

In the morphological evolution, a braided river without vegetation from initially straight channel was remarkably developed. For the braided river with vegetation, a primary channel was developed to a high meandering channel and bifucated to two channels due to vegetation on the bed and banks. This mechanism is differnt from it without vegetation.

The calcualtion results show relatively good agree- 


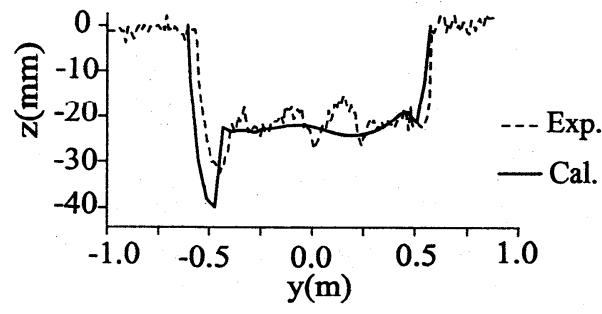

(a) $\mathrm{T}=64 \mathrm{~min}$

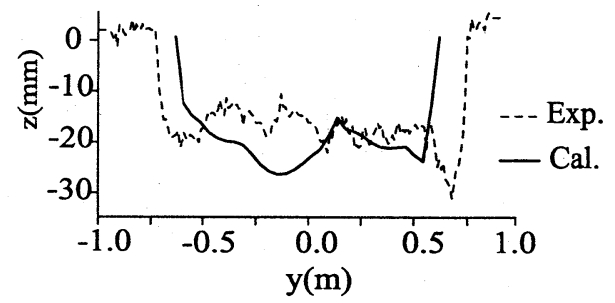

(b) $\mathrm{T}=95 \mathrm{~min}$

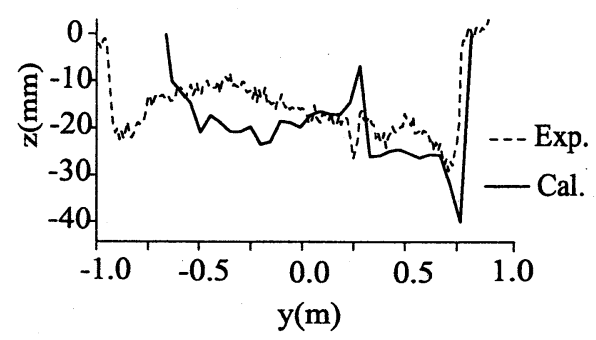

(c) $\mathrm{T}=125 \mathrm{~min}$

Fig. 8 Comparison of cross sectional change at $6 \mathrm{~m}$ for Run-1.

ments with the experimental results, although the model has some limitations. For the future, more elaborate model will be developed to simulate channel evolution considering riparian vegetation on the bed and banks.

ACKNOWLEDGEMENT: The authors are would like to thank Professor Gary Parker of the University of Minnesota, and Professor Syunsuke Ikeda of Tokyo Institute of Technology for their helpful ideas and suggestions.

\section{REFERENCES}

1) Andrwes, E. D. : Bed-material entrainment and hydraulic geometry of gravel-bed rivers in Colorado, Geol. Soc. Am. Bull., 95, 371-378, 1984.

2) Ashida, K., adn Michiue, M. : Study on hydraulic resistance and bed-load transport rate in alluvial streams, Proc. JSCE, 201, 59-69, 1972.

3) Ashmore, P.E. : Laboratory modeling of gravel braided stream morphology. Earth surf. Proc. landforms, 7, 201$225,1982$.

4) Ashmore,P.E. :How do gravel-bed rivers braid?, Can. J. Sci., 28, 326-341, 1991.

5) Bennett, S.J. , Pirim, T., and Barkdoll, B.D. : Using simulated emergent vegetation to alter stream flow direction within a straight experimental channel, Geomorphology, 44, 115-126, 2002.

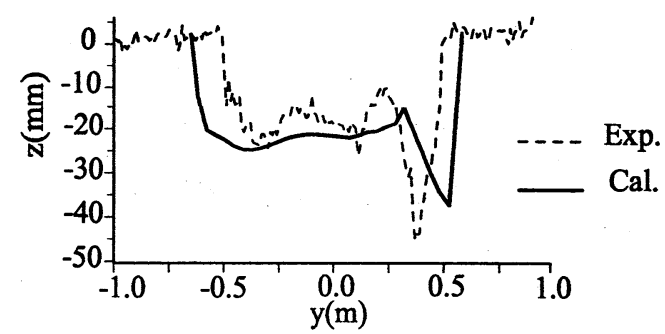

(a) $\mathrm{T}=95 \mathrm{~min}$.

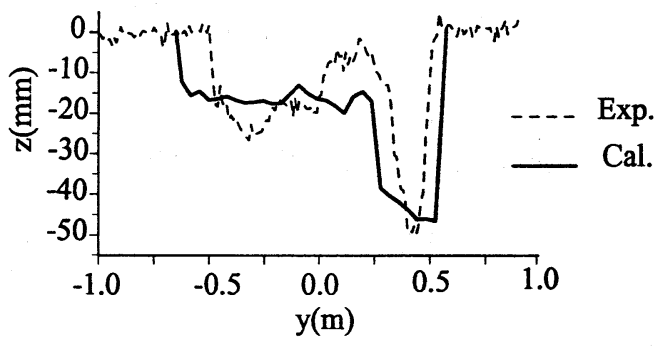

(b) $\mathrm{T}=125 \mathrm{~min}$.

Fig. 9 Comparison of cross sectional change at $6 \mathrm{~m}$ for Run-3.

6) Carollo, F.G., Ferro, V., and Termini, D. : Flow velocity measurements in vegetated channels, J. of Hyd. Eng., ASCE, 128(7), 664-673. 2002.

7) Fujita, Y., and Muramoto, Y. : Experimental study on stream channel processes in alluvial rivers, Bull. Disas. Prev. Res. Inst., Kyoto Univ., 32(288), 49-96, 1982.

8) Gran, K., and Paola, C.: Riparian vegetation controls on braided stream dynamics, Water Resour. Res., 37 (12), 3275-3283. 2001.

9) Hasegawa, K. : Hydarulic research on planimetric forms, bed topographics and flow in alluvial, $P h D$ Dissertation, Hokkaido University, Japan, 1984.

10) Hasegawa, K. : Hydraulic characteristics on mountain streams and their practical application, Lecture notes of the 33rd Summer Seminar on Hydraul. Engrg., JSCE,A9-1-20, 2000.

11) Hey, R. D., and Thorne, C. R. : Stable channels with mobile gravel beds, J. of Hyd. Eng., 112(8), 671-689, 1986. 12) Huang, H. Q., and Nanson, G. C : Vegetation and channel variation: A case study of four small streams in southeastern Australia, Geomorphology, 18, 237-249, 1997. 13)Ikeda, S., and Izumi, N.: Width and depth of selfformed straight gravel rivers with bank vegetation, Water Resour. Res., 26(10), 2353-2364,1990.

14) Kovacs. A., and Parker, G. : A new vectorial bedload formulation and its application to the time evolution of straight river channels, J. Fluid Mech, 267, 153-183, 1994. 15) Shimizu, Y., Hirano, N., and Watanabe, Y.: Numericul calcualtion of bank erosion and free meandering, Annu. J. Hydr. Engrg., JSCE, 40, 921-926, 1996.

16) Shimizu, Y.: A method for simultaneous computation of bed and bank deformation of a river, River flow 2002, Int'l Conf. on Fluvial Hydraulics, Louvain-Beuve, Belgium, 793-801, 2002.

17) Tsujimoto, T. : Fluvial processes in streams with vegetation, J. of Hydrauli. Res. 37(6), 789-803, 1999.

(Received September 30, 2002) 